\title{
Cytokine and Gene Expression Profiling in Patients with HFE-Associated Hereditary Hemochromatosis according to Genetic Profile
}

\author{
Heidi Kristine Grønlien ${ }^{a} \quad$ Trine Eker Christoffersen $^{b} \quad$ Camilla Furlund Nystrand $^{c}$ \\ Lamya Garabet $^{c, d}$ Terje Syvertsen ${ }^{c}$ Morten K. Moe ${ }^{d}$ Ole Kristoffer Olstad ${ }^{\mathrm{e}}$ \\ Christine Monceyron Jonassen ${ }^{c, f}$
}

\begin{abstract}
aFaculty of Health and Welfare Sciences, Østfold University College, Halden, Norway; ${ }^{\text {b}}$ Faculty of Engineering, Østfold University College, Halden, Norway; ${ }^{\complement}$ Center for Laboratory Medicine, Østfold Hospital Trust, Grålum, Norway; ${ }^{d}$ Department of Multidisciplinary Laboratory Medicine and Medical Biochemistry, Akershus University Hospital, Lørenskog, Norway; 'Department of Medical Biochemistry, Oslo University Hospital, Oslo, Norway; fDepartment of Chemistry, Biotechnology and Food Sciences, The Norwegian University of Life Sciences, Ås, Norway
\end{abstract}

\section{Keywords}

Hemochromatosis · Zeta globin · Hepcidin · Matrix

metallopeptidase $8 \cdot$ Iron metabolism $\cdot$ Interleukin 8

\begin{abstract}
Background: Hemochromatosis gene (HFE)-associated hereditary hemochromatosis $(\mathrm{HH})$ is characterized by downregulation of hepcidin synthesis, leading to increased intestinal iron absorption. Objectives: The objectives were to characterize and elucidate a possible association between gene expression profile, hepcidin levels, disease severity, and markers of inflammation in HFE-associated $\mathrm{HH}$ patients. Methods: Thirty-nine HFE-associated HH patients were recruited and assigned to 2 groups according to genetic profile: $\mathrm{C} 282 \mathrm{Y}$ homozygotes in 1 group and patients with H63D, as homozygote or in combination with $\mathrm{C} 282 \mathrm{Y}$, in the other group. Eleven healthy first-time blood donors were recruited as controls. Gene expression was characterized from peripheral blood cells, and inflammatory cytokines and hepcidin-25 isoform were quantified in serum. Biochemical disease characteristics were recorded. Results: Elevated levels of interleukin 8 were observed in a significant higher proportion of patients than controls. In addition, compared to controls, gene expression of $\zeta$-globin was significantly increased
\end{abstract}

karger@karger.com www.karger.com/aha

Karger"

BOPEN ACCESS
(C) 2020 The Author(s)

Published by S. Karger AG, Basel

This is an Open Access article licensed under the Creative Commons Attribution-NonCommercial-4.0 International License (CC BY-NC) (http://www.karger.com/Services/OpenAccessLicense), applicable to the online version of the article only. Usage and distribution for commercial purposes requires written permission. among C282Y homozygote patients, while gene expression of matrix metalloproteinase 8 , and other neutrophil-secreted proteins, was significantly upregulated in patients with H63D. Conclusion: Different disease signatures may characterize $\mathrm{HH}$ patients according to their HFE genetic profile. Studies on larger populations, including analyses at protein level, are necessary to confirm these findings.

(C) 2020 The Author(s)

Published by S. Karger AG, Basel

\section{Introduction}

Hereditary hemochromatosis ( $\mathrm{HH})$ is an autosomal recessive disorder caused by mutations in genes involved in iron metabolism, which results in increased intestinal iron absorption. The clinical manifestations are related to excessive iron accumulation in parenchymal cells of vital organs such as the liver, heart, and endocrine glands in particular. Thus, patients may develop liver disease, arthralgia/arthritis, diabetes mellitus, impotence, skin pigmentation, and heart enlargement.

$\mathrm{HH}$ is most commonly associated with mutations in the hemochromatosis gene (HFE) [1-5]. The HFE gene

H.K. Grønlien and T.E. Christoffersen contributed equally to this work. 
encodes the HFE protein, a nonclassical major histocompatibility type Ib membrane protein, which interacts with the transferrin receptors TfR 1 and TfR 2 at the cell surface. This interaction controls normal expression of hepcidin, a key hormone regulating iron homeostasis $[3,5]$. HFE is expressed in a wide range of tissues and cells, including Kupffer and epithelial cells of the liver, enterocytes of the duodenum, and gastric epithelial cells, as well as macrophages, circulating monocytes, and granulocytes. Conversely, HFE has been shown to localize inside the intracellular granules in granulocytes [6]. Different splice variants of the HFE gene have been identified in different tissues, expressed at different levels, and include a soluble variant produced in the duodenum, lacking its transmembrane domain and cytoplasmic tail [7]. The different splice variants might reflect different functions of HFE in the different tissues. In addition to its role in iron metabolism, HFE has recently emerged as a potential key molecule in the immunological response, bridging the innate and adaptive immune responses [8].

More than $80 \%$ of $\mathrm{HH}$ patients with mutations in $\mathrm{HFE}$ are homozygote for the $\mathrm{C} 282 \mathrm{Y}$ mutation that impairs correct folding and posttranslational processing of HFE needed for its cell surface expression [9]. An additional $14 \%$ of $\mathrm{HH}$ patients harbor a H63D mutation, either as heterozygote with $\mathrm{C} 282 \mathrm{Y}$ or as homozygote $[1-3,10]$. The H63D mutation does not alter the cell surface expression of HFE but rather alters its affinity for TfR1 [11]. Those patients tend to have a lower degree of iron load compared with C282Y homozygotes [3, 12]. For other genotypes, a small enhancement in iron absorption may occur, but this rarely results in clinically relevant iron modification and development of $\mathrm{HH}[1,3]$. Heterozygous HFE mutation is common in Caucasian populations. The overall allele frequency for $\mathrm{C} 282 \mathrm{Y}$ mutation is $7-8 \%$ in the Norwegian population [13-16].

The initial diagnostic approach is by finding elevated transferrin saturation (TfSat) and an increased serum or plasma ferritin above the upper limits of normal without the presence of significant inflammation or infection. Different studies have used different TfSat cutoff values, but TfSat $\geq 45 \%$ has high sensitivity for detecting C282Y homozygotes. Current treatment guidelines for $\mathrm{HH}$ patients are phlebotomy (venesection) and dietary advice [17]. Phlebotomy is performed when serum ferritin (SF) levels exceed $300-1,000 \mu \mathrm{g} / \mathrm{L}$ or when patients are symptomatic.

Hepcidin is produced in the liver and is a key regulator of systemic iron homeostasis $[1,5,10]$. The synthesis of hepcidin is normally upregulated by high iron blood lev- els, inflammation, or as a response to infection. Hepcidin binds to the cellular iron exporter ferroportin (FPN) located on the basolateral membrane of hepatocytes and enterocytes and in macrophages and thereby restrains iron from entering the blood circulation $[1,5,10]$. Hepcidin exists in several isoforms (hepcidin-25, $-24,-23,-22$, -20 , and -19) [18], but hepcidin-25 (Hep25) has the highest affinity for FPN, and it is this isoform that has a central role in iron regulation [19]. Hep25 synthesis in $\mathrm{HH}$ patients is downregulated causing excess FPN-mediated iron export and increased dietary iron uptake from enterocytes in the intestine and iron export from macrophages. Consequently, increased iron levels in the blood stream are observed $[1,4,5]$. The altered immunological status observed in HFE-associated $\mathrm{HH}$ patients is mainly due to iron overload, leading, for example, to lower levels of circulating invariant natural killer cells [20] or lower levels of cytokine production in macrophages [21]. In $\mathrm{C} 282 \mathrm{Y} \mathrm{HH}$ patients, the lower levels of expression of MHC class I molecules shown in peripheral mononuclear cells have been attributed to impaired intracellular trafficking due to HFE failing to bind to $\beta 2$-microglobulin $[22,23]$. A recent in vitro study evidenced a difference between wild-type and C282Y HFE proteins in their ability to activate $\mathrm{CD} 8+\mathrm{T}$ lymphocytes, suggesting that C282Y mutation may confer a stronger cellular immunity response in individuals harboring it [24]. On the other hand, autoimmune conditions are common among $\mathrm{HH}$ patients [25].

Gene expression profiling has proved useful in identifying unique signatures in a range of diseases [26-29]. Given the ubiquitous expression of HFE and its potential role in immunological processes, one main aim of the present study was to analyze gene expression from peripheral blood cells of $H F E$-associated $\mathrm{HH}$ patients according to their genetic profile, in order to identify novel molecular characteristics of the disease that may prove useful as biomarkers. The other aim was to characterize inflammatory cytokine profiles, hepcidin levels, and iron status in the patient population, to elucidate possible associations between these parameters.

\section{Materials and Methods}

Study Population and Ethics

Samples from 39 consecutive hemochromatosis patients, with known HFE mutation status and confirmed high SF levels, were collected. Information on whether the patients had phlebotomy treatment within the last 6 months prior to study inclusion was recorded. Patients who were $\mathrm{C} 282 \mathrm{Y}$ homozygotes were assigned to 
patient group 1 and those who were H63D homozygotes or H63D/ $\mathrm{C} 282 \mathrm{Y}$ compound heterozygotes were assigned to patient group 2. Control samples were collected from 11 healthy newly recruited blood donors, who had never given blood prior to their enrollment in the study. Study participants in the control group were selected with regard to sex and age to match as much as possible the patient groups.

\section{Sample Collection}

Peripheral venous blood samples were collected according to the standard operating procedures at Østfold Hospital Trust, Norway. Serum samples were collected in Vacuette ${ }^{\circledR}$ tubes $9 \mathrm{~mL} \mathrm{Z} \mathrm{Se-}$ rum Separator Clot Activator (Greiner Bio-One, Kremsmünster, Austria) and allowed to clot at room temperature for $1 \mathrm{~h}$ prior to centrifugation at 2,100 $\mathrm{g}$ for $10 \mathrm{~min}$. Serum was removed and stored at $-80^{\circ} \mathrm{C}$ until use. Samples used for mRNA and microarray analysis were collected in PAXgene Blood RNA Tubes (Qiagen, Venlo, the Netherlands), frozen stepwise, according to the manufacturer's instruction, and stored at $-80^{\circ} \mathrm{C}$ until use. Whole blood samples were collected in Vacuette ${ }^{\circledR}$ tubes $9 \mathrm{~mL} \mathrm{K2E} \mathrm{K2EDTA}$ (Greiner Bio-One) and stored at room temperature for maximum $1 \mathrm{~h}$ prior to analysis.

\section{Hematological Analysis and Liver Enzymes}

Hematological parameters including hemoglobin, erythrocytes, erythrocyte volume fraction, mean corpuscular volume, erythrocyte particle concentration, mean corpuscular hemoglobin, reticulocyte hemoglobin content, and reticulocyte count) were analyzed within $1 \mathrm{~h}$ after obtaining the samples on a CELLDYN Sapphire hematology analyzer (Abbott, Chicago, IL, USA). Iron status parameters including serum iron, ferritin, transferrin, and total iron-binding capacity and liver enzymes including alanine aminotransferase, gamma-glutamyl transferase, and alkaline phosphatase were measured on ADVIA Chemistry System (Siemens, München, Germany). TfSat was calculated from total ironbinding capacity and iron serum values. Soluble transferrin receptors were analyzed in thawed serum samples using UniCel Dxl 800 (Beckman Coulter, Brea, CA, USA).

\section{Hepcidin Isolation and Quantification}

Hep25 was analyzed on 49 samples from patients and control, as one sample in group 2 was not available for analysis. Isotope-labeled $\left(\left[{ }^{13} \mathrm{C}_{9},{ }^{15} \mathrm{~N}\right] \mathrm{Phe} 4,9\right)$ Hep25 (Bachem, Bubendorf, Switzerland) was used as internal standard $(100 \mathrm{ng} / \mathrm{mL}$ in aqueous $0.1 \%$ formic acid), where $100-\mu \mathrm{L}$ internal standard solution was added to $200-\mu \mathrm{L}$ serum. Hepcidin was isolated by solid phase extraction as described [30], except $2 \times 80 \mu \mathrm{L}$ acetonitrilewater-acetic acid (50:50:2, v/v) was used for elution. The extracts were analyzed by liquid chromatography high-resolution mass spectrometry on an Accela open autoinjector, Accela 1250 pump, and a Q Exactive mass spectrometer (Thermo Scientific, Waltham, MA, USA). Separation was conducted on a Polaris C18A (50 $\times 2 \mathrm{~mm}$; Agilent) reversed-phase chromatography column, using a gradient from $20 \%$ acetonitrile in $0.1 \%$ formic acid in water $(t=0 \mathrm{~min})$ linearly increased to $70 \%$ acetonitrile over 5 min. Hep25 was quantified by extracting the mass traces of the first 4 isotopomers of $[\mathrm{M}+4 \mathrm{H}]^{4+}$ (i.e., $m / z 697.7637,698.0144$, 698.2644 , and 698.5145 ) with a width of 8 ppm. Hep25 spiked at $2,8,32,64$, and $256 \mathrm{ng} / \mathrm{mL}$ in rabbit serum was used as calibrators.

\section{Inflammation Cytokines and Chemokines}

Twelve inflammatory cytokines and chemokines (IL1A, IL1B, IL2, IL4, IL6, IL8, IL10, IL12, IL17A, IFN $\gamma$, TNFa, and GM-CSF) were profiled in serum using Multi-Analyte ELISArray Kit (Qiagen). The detection was performed using Epoch ${ }^{\mathrm{TM}}$ Microplate Spectrophotometer (BioTek, Winooski, VT, USA) and analyzed using the Gen 5 software (BioTek). Optical density values obtained in ELISA were used to detect whether elevated levels of the different cytokines were observed in serum and to compare levels of cytokines in serum with other parameters in the study.

\section{RNA Extraction from Whole Blood}

Total RNA from whole blood stabilized in PAXgene Blood RNA Tubes was isolated and purified using the PAXgene Blood miRNA kit (Qiagen) and stored at $-80^{\circ} \mathrm{C}$ until use. RNA integrity was confirmed using Agilent RNA 6000 Pico Kit (Agilent Technologies, Santa Clara, CA, USA) and Agilent 2100 Bioanalyzer (Agilent Technologies).

\section{Microarray}

Gene expression profiling was performed on 12 randomly selected samples in group 1 and 6 of each group 2 and the control group. GeneChip WT PLUS Reagent Kit was used on total RNA (150 ng) as described by the manufacturer's instructions for whole genome gene expression analysis (Affymetrix, Santa Clara, CA, USA). Labeled and fragmented single-stranded cDNAs were hybridized to GeneChip Human Gene 2.0 ST Arrays (Affymetrix) covering 40,716 RefSeq transcripts. The arrays were washed and stained using the FS-450 fluidics station (Affymetrix). Signal intensities were detected by Hewlett Packard Gene Array Scanner 3000 7G (Hewlett Packard, Palo Alto, CA, USA). The scanned images were processed using AGCC (Affymetrix GeneChip Command Console) software (Affymetrix).

Further bioinformatics analysis was conducted on the transcripts considered significant in the statistical analysis $(p<0.05$ and FC $>1.2$ ) to identify functional significance by means of Ingenuity Pathways Analysis (IPA) (Ingenuity Systems, Redwood City, CA, USA). In brief, the data set containing gene identifiers and corresponding fold changes and $p$ values was uploaded into the web-delivered application, and each gene identifier was mapped to its corresponding gene object in the Ingenuity Pathways Knowledge Base. The functional analysis identified the biological functions and/or diseases that were most significant to the data sets. Fisher's exact test was performed to calculate the $p$ value determining the probability that each biological function and/or disease assigned to the data set was due to chance alone. The data sets were mined for significant pathways with the IPA library of canonical pathways, and networks were generated by using IPA as graphical representations of the molecular relationships between genes and gene products.

\section{cDNA Synthesis and $q P C R$}

Ten $\mu$ l of total RNAs were converted to single-stranded cDNA by using High-Capacity cDNA Reverse Transcription Master Mix as instructed (Applied Biosystems, Foster City, CA, USA). Individual TaqMan Gene Expression Assays (Applied Biosystems) were performed for the following genes: human $\zeta$-globin, $(\mathrm{HBZ}$; Assay ID: Hs00923579_m1), lactotransferrin (LTF; Assay ID: Hs00914334_m1), matrix metallopeptidase 8 (MMP8; Assay ID: Hs01029057_m1), $\alpha$-defensin (DEFA1, DEFA3, and DEFA1B; As- 
say ID: Hs00234383_m1), major histocompatibility complex, class II, DR beta 1 (HLA-DRB1; Assay ID: Hs04192464_mH), major histocompatibility complex, class II, DR beta 5 (HLA-DRB5; Assay ID: Hs02340983_m1), and tyrosine 3-monooxygenase/tryptophan 5-monooxygenase activation protein zeta ( $Y W H A Z-1$; Assay ID: Hs03044281_g1) using TaqMan Gene Expression Master Mix (Applied Biosystems). PCR was performed with $4-\mu \mathrm{L}$ cDNA in a $20-\mu \mathrm{L}$ total reaction, and the PCR conditions were $50^{\circ} \mathrm{C}$ for $2 \mathrm{~min}$ and $95^{\circ} \mathrm{C}$ for $10 \mathrm{~min}$, followed by 40 cycles of $95^{\circ} \mathrm{C}$ for $15 \mathrm{~s}$ and $60^{\circ} \mathrm{C}$ for $1 \mathrm{~min}$. YWHAZ-1 was selected as a reference gene for normalization based on its low CV (\%) in microarray analyses and similar use in previous reports [31,32]. Relative gene expression was quantified by differences in the cycle threshold in qPCR $(\Delta C t)$. HLA-DRB1 and HLA-DRB2 verification assays were performed on 9 of 11 controls, 24 of 26 individuals in group 1 , and 12 of 13 individuals in group 2 due to restricted amount of RNA in several samples.

\section{Data Analysis and Statistics}

Descriptive analyses and frequencies were employed to assess sample characteristics. Data distributions were tested for normality in all cases. Comparisons of blood markers of iron status, hematological parameters, inflammation, liver enzymes, and mRNA profiles were performed using one-way analyses of variance (ANOVA) followed by Tukey's post hoc test. To account for nonnormality, comparisons were assessed using the Kruskal-Wallis test followed by Mann-Whitney U tests. Fisher's exact test was used to compare proportions. Independent sample $t$ test or, to account for nonnormality, Mann-Whitney $U$ test was performed for comparison of binary variables. To assess possible associations between variables, Pearson's correlation $(r)$ or, to account for nonnormality, Spearman's product-moment correlation (rho) was used. A $p$ value of $<0.05$ was defined as statistically significant. All the analyses of blood markers were performed using SPSS 23 for Windows (IBM, Armonk, NY, USA).

For gene expression analysis, the Affymetrix CEL files (containing probe intensities) were imported into Partek Genomics Suite software (Partek Inc., Chesterfield, MO, USA) for statistical analysis. Robust microarray analysis yielding normalized log2transformed signal intensities was applied for normalization. Gene transcripts with maximal signal values of $<5$ ( $\log 2$ values) across all arrays were removed to filter for low- and nonexpressed genes, reducing the number of transcripts to 18,857 . Differentially expressed transcripts between groups were identified using one-way ANOVA as implemented in Partek Genomics Suite (Partek Inc.). Transcripts with $p<0.05$ and FC $>1.2$ were considered as significant.

\section{Results}

\section{Demographic Data and Biochemical Disease}

Characteristics in the Study Population

Biochemical disease characteristics, including iron status, hematological parameters, hepcidin, and liver enzymes, were determined for 50 subjects from South East Norway, as presented in Table 1 along with demographic

Cytokine and Gene Expression Profiling in Hereditary Hemochromatosis Patients data, mutational status, phlebotomy status, and previous highest measured SF levels. These parameters were compared within the patient groups and between patient groups and the control group.

TfSat levels in HFE C282Y homozygotes (group 1) were significantly higher than in subjects with HFE H63D mutation (group 2) and healthy individuals (control group) $(p<0.05)$. The differences in TfSat levels were slightly above significance level between group 2 and the control group $(p=0.051)$. Similarly, mean corpuscular volume in group 1 was significantly increased compared to the control group ( $p<0.05$ ), while no differences were detected between group 2 and the control group ( $p=0.094$ ). Mean corpuscular hemoglobin and reticulocyte hemoglobin content were elevated in both patient groups compared to the control group ( $p<$ 0.001 ), while levels of liver enzymes did not differ between any patient groups compared to healthy individuals.

The Hep25 concentration was significantly lower in the 2 patient groups compared to the control group $(p<$ $0.001)$, but there was no difference in Hep25 level between group 1 and group $2(p=0.588)$. In both patient groups, more than half of the patients had no detectable Hep25 in their serum. To elucidate if a small amount of Hep25 could be associated with any of the disease severity parameters in this study, statistical tests were conducted to compare these parameters for the dichotomic variable, detectable Hep 25 or not detectable Hep 25 within the patients. Ferritin was the only variable displaying significant higher values for patients with detectable Hep25 (median 198, IQR $=291, n=17$ ) compared to patients with no detectable Hep25 (median $=86, \mathrm{IQR}=282, n=$ 21; $U=96, z=2.42, p=0.015, r=0.44)$. When further dividing patients between those who did receive phlebotomy the last 6 months prior to study enrollment and those who did not, no significant difference in Hep25 could be observed in association with phlebotomized status $(p=0.674)$.

\section{Cytokine Profiles}

Several cytokines were analyzed (IL1 $\alpha$, IL1 $\beta$, IL2, IL4, IL6, IL8, IL10, IL12, IL17, IFN $\gamma$, TNF $\alpha$, and Gm-CSF) in order to investigate the inflammatory status of the study population. As opposed to none of the individuals in the control group, $42 \%$ and $46 \%$ of the patients in groups 1 and 2, respectively, had elevated levels of IL8 in serum $\left(\chi^{2}\right.$ $=7.32, \mathrm{df}=2, p=0.026)$. No significant differences between the patients and control group were observed for any other of the cytokines (Table 2). 
Table 1. Characteristics of demographics and blood markers of iron status, hematological parameters, and liver enzymes in HH patient groups (1-2) compared to the control group (3)

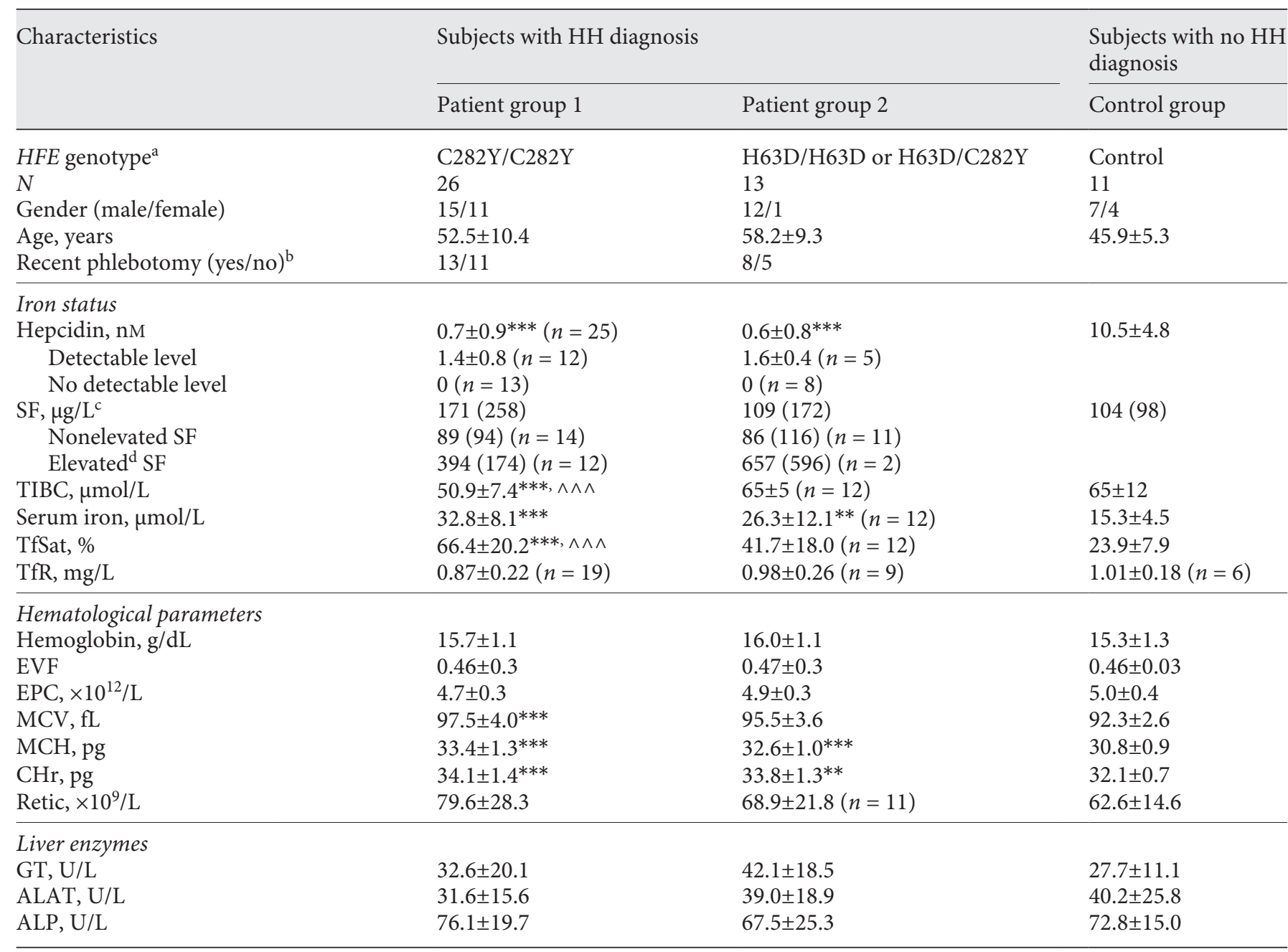

Data are presented as mean $\pm \mathrm{SD}$, unless indicated otherwise. $\mathrm{HH}$, hereditary hemochromatosis; HFE, hemochromatosis gene; SF, serum ferritin; TIBC, total iron-binding capacity; TfSat, transferrin saturation; TfR, transferrin receptor; EVF, erythrocyte volume fraction (hematocrit); EPC, erythrocyte particle concentration; MCV, mean corpuscular volume erythrocytes; $\mathrm{MCH}$, mean corpuscular hemoglobin erythrocytes; $\mathrm{CHr}$, reticulocyte hemoglobin content; Retic, reticulocyte count; GT, gamma-glutamyl transferase; ALAT, alanine aminotransferase; ALP, alkaline phosphatase. ${ }^{a} \mathrm{C} 282 \mathrm{Y}, \mathrm{cDNA}$, nucleotide $845 \mathrm{G} \rightarrow \mathrm{A} ; \mathrm{H} 63 \mathrm{D}$, cDNA, nucleotide $187 \mathrm{C} \rightarrow \mathrm{G}$. ${ }^{\mathrm{b}}$ Two individuals were blood donors, not included. ${ }^{\mathrm{c}}$ Presented as median (interquartile range). ${ }^{\mathrm{d}}$ Elevated SF is defined as $>300$ and $>200 \mu \mathrm{g} / \mathrm{L}$ in men and women, respectively. ${ }^{* *} p<0.01,{ }^{* * *} p<0.001$ compared to control; ${ }^{\wedge \wedge} p<0.001$ compared to the HH group.

Several patients among those who underwent phlebotomy within the last 6 months had elevated IL8 level ( $n=$ $13 / 21)$ compared to patients who were not recently phlebotomized $(n=4 / 12)\left(\chi^{2}=4.98, \mathrm{df}=1, p=0.045\right)$. We observed no other statistical differences in disease parameters in this study between patients with elevated levels of IL8 in serum and the patients with no IL8 in serum.
Gene Expression Profiles and qPCR Analysis

Gene expression data set for the 24 randomly selected study samples is available from the Gene Expression Omnibus (GEO) database (Accession No. GSE121620). Out of the 18,857 transcripts analyzed, 19 genes were found overall to be $\geq 2$-fold up- or downregulated in $\mathrm{HH}$ patient groups compared to healthy controls, according to their genetic profile, and 9 genes were differentially expressed 
Table 2. Cross table of inflammatory cytokine status in serum in study population

\begin{tabular}{llllll}
\hline Cytokine & $N$ & Group $1^{\mathrm{a}}(+/-)$ & Group $2^{\mathrm{b}}(+/-)$ & Control $(+/-)$ & Statistics $\left(\chi^{2}, \mathrm{df}, p\right)$ \\
\hline IL1 $\alpha$ & 50 & $4 / 22$ & $3 / 10$ & $5 / 6$ & $\chi^{2}=3.84, \mathrm{df}=2, p=0.147$ \\
IL1 $\beta$ & 50 & $6 / 20$ & $3 / 10$ & $3 / 8$ & $\chi^{2}=0.083, \mathrm{df}=2, p=0.959$ \\
IL2 & 50 & $5 / 21$ & $4 / 9$ & $6 / 5$ & $\chi^{2}=4.59, \mathrm{df}=2, p=0.100$ \\
IL4 & 50 & $3 / 23$ & $4 / 9$ & $4 / 7$ & $\chi^{2}=3.56, \mathrm{df}=2, p=0.168$ \\
IL6 & 50 & $3 / 23$ & $1 / 12$ & $1 / 10$ & $\chi^{2}=0.155, \mathrm{df}=2, p=0.925$ \\
IL8 & 50 & $11 / 15$ & $6 / 7$ & $0 / 11$ & $\chi^{2}=7.32, \mathrm{df}=2, p=0.026$ \\
IL10 & 50 & $6 / 20$ & $4 / 9$ & $2 / 9$ & $\chi^{2}=0.543, \mathrm{df}=2, p=0.762$ \\
IL12 & 50 & $6 / 20$ & $3 / 10$ & $5 / 6$ & $\chi^{2}=2.13, \mathrm{df}=2, p=0.345$ \\
IL17A & 50 & $9 / 17$ & $7 / 6$ & $7 / 4$ & $\chi^{2}=3.05, \mathrm{df}=2, p=0.217$ \\
IFN $\gamma$ & 50 & $7 / 19$ & $5 / 8$ & $6 / 5$ & $\chi^{2}=2.60, \mathrm{df}=2, p=0.272$ \\
TNF 2 & 50 & $5 / 21$ & $2 / 11$ & $2 / 9$ & $\chi^{2}=0.087, \mathrm{df}=2, p=0.957$ \\
Gm-CSF & 50 & $4 / 22$ & $5 / 8$ & $5 / 6$ & $\chi^{2}=4.42, \mathrm{df}=2, p=0.110$ \\
\hline
\end{tabular}

${ }^{\mathrm{a}} \mathrm{HFE}$ genotype C282Y/C282Y. ${ }^{\mathrm{b}} \mathrm{HFE}$ genotype H63D/H63D or H63D/C282Y.

in $\mathrm{C} 282 \mathrm{Y}$ homozygotes, compared to $\mathrm{H} 63 \mathrm{D}$ harboring patients (Table 3 ). When collectively comparing all samples from the 2 patient groups to healthy controls under IPA or when comparing each patient group to healthy controls, pathways related to inflammatory response, infectious disease, respiratory disease, hematological disease, dermatological diseases and condition, organismal injury and abnormalities, and cancer were identified (see online suppl. files 1-3; for all online suppl. material, see www.karger.com/doi/10.1159/000511551).

$\zeta$-Globin (HBZ), $\alpha$-defensin (DEFA1, DEFA1B, and $D E F A 3)$ hereafter named $D E F A$, lactotransferrin $(L T F)$, matrix metallopeptidase $8(M M P 8)$, and major histocompatibility complex, class II DR beta 1 (HLA-DRB1) and beta 5 (HLA-DRB5) genes were selected for further verification by qPCR on the study population $(n=50$ for the first 4 genes and $n=45$ for the HLA genes) based on profiling results and potential relevance to iron metabolism regulation and hemochromatosis. No fold changes were calculated for $H L A-D R B 5$, as this gene was expressed in less than half of the samples overall. No significant difference between the groups as to proportion of HLADRB5 expression was observed: $13 / 24$ individuals in group $1,4 / 12$ of individuals in group 2 , and in $6 / 9$ controls $\left(\chi^{2}=2.47, p=0.29\right)$. For the other genes, fold changes in gene expression for the individual qPCRs are presented in Table 4.

Gene expression levels of HBZ were significantly increased among C282Y homozygote patients, by $>3$-fold compared to healthy controls (Table 4). No significant al- teration in $H B Z$ expression was detected for patients with the H63D mutation in group 2.

MMP8 gene expression was upregulated in patients with H63D mutation by $>3$-fold compared to healthy controls, while patients who were homozygote for $\mathrm{C} 282 \mathrm{Y}$ did not show any significant change in MMP8 gene expression. Similarly, gene expression of DEFA and LTF was significantly upregulated in patients with the H63D mutation, while the upregulation was not significant in C282Y homozygotes (Table 4).

No significant difference in gene expression of HLADRB1 between either of the patient groups and the control group could be confirmed by qPCR (Table 4). When further dividing patients in the $\mathrm{C} 282 \mathrm{Y}$ homozygotous group between those who did receive phlebotomy the last 6 months prior to study enrollment ( $n=11$ for HLADRB1 and $n=12$ for the other genes) and those who did $\operatorname{not}(n=11$ for $H L A-D R B 1$ and $n=12$ for the other genes), no significant differences between these subgroups were observed for any of the genes.

Statistical analysis of possible associations between upregulated gene expression and the disease parameters in this study revealed for $H B Z$ no significant bivariate correlations within the $\mathrm{C} 282 \mathrm{Y}$ homozygotous group. Within the patients harboring an H63D mutation, MMP8 levels correlated with levels of SF (rho $[\rho]=0.599, p=0.031$, $n=13$ ), and there was a significantly lower level of LTF in patients with no detectable Hep25 in serum compared to patients with a small amount of Hep25 $(t[11]=2.404$, $p=0.035$, eta square $=0.34, n=13$ ).

Acta Haematol 2021;144:446-457 451 
Table 3. Fold change ( $\geq 2$-fold) in gene expression in $\mathrm{HH}$ patient groups (1-2) compared to the control group analyzed by microarray

\begin{tabular}{|c|c|c|c|c|c|}
\hline $\begin{array}{l}\text { Patient } \\
\text { group }^{\mathrm{a}}\end{array}$ & Gene symbol & Gene assignment & Biological process & $\begin{array}{l}\text { Fold } \\
\text { change }\end{array}$ & $p$ value \\
\hline \multirow[t]{5}{*}{1} & $H L A-D R B 5$ & $\begin{array}{l}\text { Major histocompatibility complex, class II, } \\
\text { DR beta } 5\end{array}$ & $\begin{array}{l}\text { Immunoglobulin production, involved in } \\
\text { immunoglobulin-mediated immune response }\end{array}$ & 18.7 & 0.037 \\
\hline & $H L A-D R B 1$ & $\begin{array}{l}\text { Major histocompatibility complex, class II, } \\
\text { DR beta } 1\end{array}$ & $\begin{array}{l}\text { Immunoglobulin production involved in } \\
\text { immunoglobulin-mediated immune response }\end{array}$ & 13.4 & 0.035 \\
\hline & $D E F A 3$ & a-Defensin 3 , neutrophil specific & $\begin{array}{l}\text { Innate immune response in mucosa, antimicrobial } \\
\text { humoral response }\end{array}$ & 2.3 & 0.022 \\
\hline & $M T-T D$ & Mitochondrially encoded tRNA aspartic acid & - & 2.2 & 0.010 \\
\hline & $C F D$ & Complement factor D (adipsin) & $\begin{array}{l}\text { Complement activation, proteolysis, neutrophil } \\
\text { degranulation }\end{array}$ & -2.3 & 0.004 \\
\hline \multirow[t]{11}{*}{2} & IGHJ6 & Immunoglobulin heavy joining 6 & - & 7.5 & 0.043 \\
\hline & CEACAM8 & $\begin{array}{l}\text { Carcinoembryonic antigen-related cell } \\
\text { adhesion molecule } 8\end{array}$ & Neutrophil degranulation, immune response & 5.1 & 0.008 \\
\hline & $L T F$ & Lactotransferrin & $\begin{array}{l}\text { Humoral immune response, DNA-templated } \\
\text { transcription, neutrophil degranulation, regulation of } \\
\text { cytokine production }\end{array}$ & 3.9 & 0.014 \\
\hline & MMP8 & $\begin{array}{l}\text { Matrix metallopeptidase } 8 \text { (neutrophil } \\
\text { collagenase) }\end{array}$ & $\begin{array}{l}\text { Extracellular matrix disassembly, proteolysis, neutrophil } \\
\text { degranulation }\end{array}$ & 2.8 & 0.038 \\
\hline & OLFM4 & Olfactomedin 4 & Cell adhesion, neutrophil degranulation & 2.8 & 0.005 \\
\hline & CEACAM6 & $\begin{array}{l}\text { Carcinoembryonic antigen-related cell } \\
\text { adhesion molecule } 6\end{array}$ & Signal transduction, neutrophil degranulation & 2.8 & 0.041 \\
\hline & RNU6-949P & RNA, U6 small nuclear 949, pseudogene & - & 2.3 & 0.029 \\
\hline & RNU7-22P & RNA, U7 small nuclear 22 pseudogene & - & 2.0 & $>0.001$ \\
\hline & CRISP3 & Cysteine-rich secretory protein 3 & Neutrophil degranulation, defense response & 2.0 & 0.004 \\
\hline & $G B P 1$ & $\begin{array}{l}\text { Guanylate-binding protein 1, interferon } \\
\text { inducible }\end{array}$ & $\begin{array}{l}\text { Negative regulation of: interleukin-2 secretion, T-cell } \\
\text { receptor signaling, and ERK1 and ERK2 cascade. } \\
\text { Interferon-gamma-mediated signaling pathway. }\end{array}$ & 2.0 & 0.024 \\
\hline & ZNF208 & Zinc finger protein 208 & Regulation of transcription & 2.0 & 0.014 \\
\hline
\end{tabular}

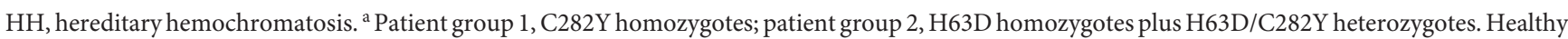
subjects were assigned to the control group.

\section{Discussion}

In this study, we have characterized a patient population with $H F E$-associated $\mathrm{HH}$ according to their genetic profile. Blood markers of iron status, hematological parameters, liver enzymes, inflammation markers, Hep25, and total gene expression from peripheral blood cells were analyzed. We found significant differences in the gene expression of $H B Z$ in patients homozygous for $\mathrm{C} 282 \mathrm{Y}$ and in the gene expression of several neutrophilassociated proteins, in particular MMP8, in patients harboring a H63D mutation. IL8 was the only proinflamma- 
Table 4. Fold change in expression of selected genes in $\mathrm{HH}$ patient groups (1-2) compared to the control group analyzed by qPCR on the study population

\begin{tabular}{llcc}
\hline Gene symbol & Gene assignment & Patient group 1 & Patient group 2 \\
\hline$H B Z$ & G-Globin & $3.3^{* *}$ & 1.2 \\
$D R B 1$ & HLA class II, DR beta 1 & -1.2 & -2.2 \\
$M M P 8$ & Matrix metallopeptidase 8 & 1.5 & $3.2^{* *}$ \\
$D E F A 1+D E F A 1 B+D E F A 3$ & a-Defensin & 1.8 & $2.9^{*}$ \\
LTF & Lactotransferrin & 1.7 & $2.3^{*}$ \\
\hline
\end{tabular}

$\mathrm{HH}$, hereditary hemochromatosis. Patient group 1, C282Y homozygotes; patient group 2, H63D homozygotes plus H63D/C282Y heterozygotes. Healthy subjects were assigned to the control group for fold change analyses. ${ }^{*} p<0.05,{ }^{* *} p<0.01$ compared to control.

tory cytokine where elevated levels were commonly detected in both patient groups, compared with controls. The results from blood markers of iron, hematological, and liver status support previous findings for $\mathrm{HH}$ patients and show that the study population is representative for this patient group [33-35].

One of the main findings reported herein is the overexpression of $H B Z$ among patients with the C282Y HFE mutation. Hemoglobin is composed of 2 a-like and 2 $\beta$-like globin chains expressed in balanced amounts in normal erythroid cells. The 2 separated $\alpha$-like and $\beta$-like globin gene clusters are subject to several levels of regulation that ensure assembly of embryonic $\left(\zeta_{2} \varepsilon_{2}\right)$, fetal $\left(\alpha_{2} \gamma_{2}\right)$, and adult $\left(\alpha_{2} \beta_{2}\right)$ hemoglobins during development [36, 37], where embryonic and fetal hemoglobins have higher affinity for oxygen than adult hemoglobin. In particular, $\zeta$-globin has a very high affinity for oxygen, allowing the embryo to capture oxygen from maternal hemoglobin through the placenta. However, delivery of oxygen to tissue is much lower with $\zeta$-globin than with $\alpha$-globin, and the switch from $\zeta$ - to $\alpha$-globin occurs through silencing within the first 10 weeks of gestation [38-40].

Nevertheless, we found that $H B Z$ was upregulated in $\mathrm{HH}$ patients homozygote for $\mathrm{C} 282 \mathrm{Y}$ with $>3$-fold compared to controls. Our observation is not the first report of $\zeta$-globin being expressed in detectable levels in adult tissue, as detection of $\zeta$-globin in subjects suffering from $\alpha$-thalassemia has previously been reported [41-43]. In addition, the presence of embryonic globin mRNAs has been reported in small amounts in adult erythroblasts and reticulocytes $[44,45]$.

Whether the upregulation of $\zeta$-globin mRNA expression in $\mathrm{C} 282 \mathrm{Y} \mathrm{HH}$ patients is a consequence of the disease or a physiological attempt to compensate for its detri- mental effects can only be speculated on at this point. The genes in the $\alpha$-globin locus are surrounded by a cluster of transcriptionally active ubiquitously expressed genes in the subtelomeric region of chromosome 16 and are expressed through histone hyperacetylation and remodeling of the local chromatin structure in erythroid cells. The major $a$-like globin gene transcriptional regulatory element, the DNase hypersensitive site HS40, is located in an intron of the adjacent housekeeping gene nitrogen permease-regulator-like gene 3 (NPRL3) [46-48]. Interestingly, data from our microarray gene expression profiling identified NPRL3 as being significantly upregulated by nearly $50 \%$ (fold change $1.49, p=0.02$ ) in C282Y HH patients compared to controls, while no upregulation of this gene was observed in H63D mutation-carrying patients. The interaction between the expression of NPRL3 and both overall expression of a-like globin genes and the possible reactivation of mRNA expression of $\zeta$-globin, that is located immediately downstream of NPRL3, remain to be elucidated. Further investigations at the protein level are required to identify whether a hypothetically semiembryonic hemoglobin such as Portland-2 $\left(\zeta_{2} \beta_{2}\right)$, a protein believed to be compatible with normal adult physiology [49], is produced in C282Y homozygotous $\mathrm{HH}$ patients and to unveil potential physiological effects on oxygen delivery to tissues and iron-catalyzed oxidative cellular damage. As no upregulation of expression of this gene was observed in $\mathrm{HH}$ patients with $\mathrm{H} 63 \mathrm{D}$ even though most of them were compound heterozygous $\mathrm{C} 282 \mathrm{Y} / \mathrm{H} 63 \mathrm{D}$, increase in $\zeta$-globin mRNA production is likely linked to a total impairment of cell surface localization of the HFE protein.

Interactions between the mechanisms of iron metabolism and inflammation have recently attracted consider- 
able attention [50-53]. It has been speculated that in $\mathrm{HH}$ patients, several health issues are likely contributed by the increased susceptibility to infection. The very high TfSat attained in patients with iron overload and considerable reduction in the antimicrobial peptide hepcidin provide the basis for favorable bacterial conditions [54-56]. Our analyses showed that several $\mathrm{HH}$ patients had elevated levels of IL8 compared to control subjects regardless of their genetic profile. It has previously been found that the C282Y HFE protein induces the transcription factor NF$\kappa \mathrm{B}$, which consequently resulted in a marked increase in protein production of IL8 along with increased transcriptional activation of IL8 in C282Y HFE-expressing cells [57]. Elevated levels of IL8 were especially observed in patients who had recently been treated with phlebotomy, which might suggest a relation between disease severity and levels of IL8. IL8 is a major activating factor of neutrophils, and, interestingly, several neutrophil-secreted proteins were found to be significantly upregulated in patients harboring the H63D mutation, such as MMP8 and antimicrobial proteins like $\alpha$-defensin 1 and lactotransferrin. The secretion of potent antimicrobial peptides might counteract the reduced levels of Hep25, in fighting bacterial infections. In addition, an anti-inflammatory role of neutrophil-derived defensins has newly been reported [58].

MMP8 is an interstitial collagenase that cleaves fibrillar collagen of types I, II, and III and has a central role in inflammatory disorders and cancer progression [59]. The liver is the site of maximal iron deposition and organ damage in this disease [5]. Progressive hepatic iron deposition commonly leads to liver fibrosis and ultimately cirrhosis. The dysregulation in the deposition and degradation of extracellular matrix occurs when activated hepatic stellate cells deposit excessive extracellular matrix components, mainly collagen I and III. Our observation of increased MMP8 transcription that correlated with SF levels in $\mathrm{HH}$ patients with the H63D mutation can suggest an antifibrotic role probably by inducing increased collagen I and III processing in fibrotic tissue. This could be supported by the study of Siller-López and coworkers [60] that showed adenoviral human MMP8 delivery in a cirrhotic rat model was accompanied with a significant decrease of a fibrotic score by $45 \%$. However, it cannot be ruled out that MMP8 has other functions in the extracellular tissue as recent studies have shown its significance as regulators of extracellular tissue signaling networks, as reviewed by Löffek and colleagues [61]. Interestingly, $\mathrm{HH}$ patients homozygote for the $\mathrm{C} 282 \mathrm{Y}$ mutation did not show a significant increase in MMP8 gene expression in our material. This may suggest that the observed upregulation of MMP8 gene expression is dependent on the mutation status. However, such implications cannot be concluded from this pilot study but require further investigations in larger populations and confirmation at the protein level.

Hepcidin is a major coordinator of iron metabolism, and its role has been extensively studied over the past decade [62-64]. The $2 \mathrm{HH}$ patient groups displayed significantly lower values of Hep25 in serum compared to the control group, half of the patients having no detectable Hep25 in serum, while the other half displayed very low levels of Hep25. Analysis of the iron status, hematological and liver tests, inflammatory cytokines, and mRNA profile by comparing the patient group with no detectable Hep25 levels with the patient group with low Hep25 levels revealed only a difference in SF concentration, where increased SF concentration was associated with detectable serum Hep25 in the HH patients. Among healthy subjects, a similar correlation has been reported $[65,66]$. It has also previously been reported that elevated ferritin levels in C282Y homozygotes were associated with higher levels of serum hepcidin [67]. However, due to the small sample size and large number of variables, the statistical analysis in this study allows for underestimation by accepting that there are no effects when the alternative is true.

\section{Conclusion}

In this study, we identified IL8 as the only inflammatory cytokine with elevated levels in a large proportion of $\mathrm{HH}$ patients, especially in those who were recently in need of phlebotomy, suggesting a potential role for this cytokine as a biomarker of disease severity. $\zeta$-Globin gene expression was highly upregulated in C282Y homozygotes but not in $\mathrm{H} 63 \mathrm{D} \mathrm{HH}$ patients or H63D/ $\mathrm{C} 282 \mathrm{Y}$, suggesting its association with hemochromatosis where cellular membrane expression of HFE is completely abolished. In addition, gene expression of MMP8 and other neutrophil-associated proteins was upregulated in $\mathrm{HH}$ patients harboring the $\mathrm{H} 63 \mathrm{D}$ mutation. Our results suggest that different disease signatures are involved in $\mathrm{HH}$ patients depending on the HFE genetic profile. However, studies on a larger population, including analysis at protein level, are necessary to confirm our findings. 


\section{Acknowledgements}

The authors thank Gerd Breivik, Annette Veberg Dahl, and Anna-Lena Kjøniksen from the Østfold University College and Anbjørg Rangberg from Østfold Hospital Trust for their contributions.

\section{Statement of Ethics}

The study was approved by the Norwegian Regional Committee for Medical and Health Research Ethics, South East Region (2014/1732). Written information on the study was given to all patients and controls, and written informed consent was obtained from all study participants.

\section{Conflict of Interest Statement}

The authors have no conflicts of interest to disclose.

\section{Funding Sources}

The study was funded by the Oslofjordfondet (Project No. 239139), the Østfold Hospital Trust, and the Østfold University College.

\section{Author Contributions}

Conceptualization: Heidi K. Grønlien, Terje Syvertsen, Trine E. Christoffersen, Lamya Garabet, Camilla F. Nystrand, and Christine M. Jonassen. Data curation: Camilla F. Nystrand, Trine E. Christoffersen, Terje Syvertsen, Morten K. Moe, Ole Kristoffer Olstad, and Christine M. Jonassen. Formal analysis: Heidi K. Grønlien, Camilla F. Nystrand, Trine E. Christoffersen, Morten K. Moe, Ole Kristoffer Olstad, and Christine M. Jonassen. Funding acquisition: Trine E. Christoffersen and Christine M. Jonassen. Investigation: Heidi K. Grønlien, Camilla F. Nystrand, Trine E. Christoffersen, Terje Syvertsen, Lamya Garabet, Morten K. Moe, Ole Kristoffer Olstad, and Christine M. Jonassen. Methodology: Heidi K. Grønlien, Camilla F. Nystrand, Trine E. Christoffersen, Terje Syvertsen, Morten K. Moe, Ole Kristoffer Olstad, and Christine M. Jonassen. Project administration: Heidi K. Grønlien and Christine M. Jonassen. Resources: Heidi K. Grønlien, Terje Syvertsen, and Christine M. Jonassen. Supervision: Heidi K. Grønlien and Christine M. Jonassen. Visualization: Heidi K. Grønlien, Ole Kristoffer Olstad, Camilla F. Nystrand, and Christine M. Jonassen. Writing original draft: Heidi K. Grønlien, Trine E. Christoffersen, Camilla F. Nystrand, Morten K. Moe, Lamya Garabet, Ole Kristoffer Olstad, and Christine M. Jonassen. Writing - review and editing: Heidi K. Grønlien, Trine E. Christoffersen, Camilla F. Nystrand, Morten K. Moe, Lamya Garabet, Terje Syvertsen, Ole Kristoffer Olstad, and Christine M. Jonassen.

\section{References}

1 Pietrangelo A. Hereditary hemochromatosis: pathogenesis, diagnosis, and treatment. Gastroenterology. 2010 Aug; 139(2):393-408, 408.e1-2.

2 Crownover BK, Covey CJ. Hereditary hemochromatosis. Am Fam Physician. 2013 Feb 1; 87(3):183-90.

3 Vujic M. Molecular basis of HFE-hemochromatosis. Front Pharmacol. 2014;5:42.

4 Powell LW, Seckington RC, Deugnier Y. Haemochromatosis. Lancet. 2016 Aug 13; 388(10045):706-16.

5 Hollerer I, Bachmann A, Muckenthaler MU. Pathophysiological consequences and benefits of HFE mutations: 20 years of research. Haematologica. 2017 May;102(5):809-17.

6 Parkkila S, Parkkila AK, Waheed A, Britton RS, Zhou XY, Fleming RE, et al. Cell surface expression of HFE protein in epithelial cells, macrophages, and monocytes. Haematologica. 2000;85(4):340-5.

7 Martins M, Rosa A, Guedes LC, Fonseca BV, Gotovac K, Violante S, et al. Convergence of miRNA expression profiling, $\alpha$-synuclein interacton and GWAS in Parkinson's disease. PLoS One. 2011;6(10):e25443.

8 Reuben A, Chung JW, Lapointe R, Santos MM. The hemochromatosis protein HFE 20 years later: an emerging role in antigen presentation and in the immune system. Immun Inflamm Dis. 2017 Sep;5(3):218-32.
9 Waheed A, Parkkila S, Zhou XY, Tomatsu S, Tsuchihashi Z, Feder JN, et al. Hereditary hemochromatosis: effects of C282Y and H63D mutations on association with beta2-microglobulin, intracellular processing, and cell surface expression of the HFE protein in COS-7 cells. Proc Natl Acad Sci U S A. 1997 Nov 11;94(23):12384-9.

10 Pietrangelo A. Genetics, genetic testing, and management of hemochromatosis: 15 years since hepcidin. Gastroenterology. 2015 Oct; 149(5):1240-51.e4.

11 Lebron JA, Bennett MJ, Vaughn DE, Chirino AJ, Snow PM, Mintier GA, et al. Crystal structure of the hemochromatosis protein HFE and characterization of its interaction with transferrin receptor. Cell. 1998 Apr 3;93(1):111-23.

12 European Association for the Study of the Liver. EASL clinical practice guidelines for HFE hemochromatosis. J Hepatol. 2010 Jul; 53(1):3-22.

13 Distante S, Berg JP, Lande K, Haug E, Bell H. High prevalence of the hemochromatosis-associated Cys282Tyr HFE gene mutation in a healthy Norwegian population in the city of Oslo, and its phenotypic expression. Scand J Gastroenterol. 1999 May;34(5):529-34.

14 Asberg A, Hveem K, Thorstensen K, Ellekjter E, Kannelønning K, Fjøsne U, et al. Screening for hemochromatosis: high prevalence and low morbidity in an unselected population of 65,238 persons. Scand J Gastroenterol. 2001 Oct;36(10):1108-15.
15 Distante S. Genetic predisposition to iron overload: prevalence and phenotypic expression of hemochromatosis-associated HFEC282Y gene mutation. Scand J Clin Lab Invest. 2006;66(2):83-100.

16 Thorstensen K, Kvitland MA, Irgens WØ, Hveem K, Asberg A. Screening for C282Y homozygosity in a Norwegian population (HUNT2): the sensitivity and specificity of transferrin saturation. Scand J Clin Lab Invest. 2010 Apr;70(2):92-7.

17 Bacon BR, Adams PC, Kowdley KV, Powell LW, Tavill AS. Diagnosis and management of hemochromatosis: 2011 practice guideline by the American Association for the Study of Liver Diseases. Hepatology. 2011;54(1):32843.

18 Moe MK, Hardang IM, Hagve TA. Novel circulating isoforms of hepcidin. Clin Chem. 2013 Sep;59(9):1412-4.

19 Nemeth E, Roetto A, Garozzo G, Ganz T, Camaschella C. Hepcidin is decreased in TFR2 hemochromatosis. Blood. 2005 Feb 15; 105(4):1803-6.

20 Maia ML, Pereira CS, Melo G, Pinheiro I, Exley MA, Porto G, et al. Invariant natural killer $\mathrm{T}$ cells are reduced in hereditary hemochromatosis patients. J Clin Immunol. 2015 Jan; 35(1):68-74. 
21 Wang L, Johnson EE, Shi HN, Walker WA, Wessling-Resnick M, Cherayil BJ. Attenuated inflammatory responses in hemochromatosis reveal a role for iron in the regulation of macrophage cytokine translation. J Immunol. 2008 Aug 15;181(4):2723-31.

22 de Almeida SF, Carvalho IF, Cardoso CS, Cordeiro JV, Azevedo JE, Neefjes J, et al. HFE cross-talks with the MHC class I antigen presentation pathway. Blood. 2005 Aug 1;106(3): 971-7.

23 de Almeida SF, Picarote G, Fleming JV, Carmo-Fonseca M, Azevedo JE, de Sousa M. Chemical chaperones reduce endoplasmic reticulum stress and prevent mutant HFE aggregate formation. J Biol Chem. 2007 Sep 21; 282(38):27905-12.

24 Reuben A, Phenix M, Santos MM, Lapointe R. The WT hemochromatosis protein HFE inhibits CD8(+) T-lymphocyte activation. Eur J Immunol. 2014 Jun;44(6):1604-14.

25 Barton JC, Barton JC. Autoimmune conditions in 235 hemochromatosis probands with HFE C282Y homozygosity and their first-degree relatives. J Immunol Res. 2015;2015: 453046.

26 Mesko B, Poliska S, Szegedi A, Szekanecz Z, Palatka K, Papp M, et al. Peripheral blood gene expression patterns discriminate among chronic inflammatory diseases and healthy controls and identify novel targets. BMC Med Genomics. 2010 May 5;3:15.

27 Nickles D, Chen HP, Li MM, Khankhanian P, Madireddy L, Caillier SJ, et al. Blood RNA profiling in a large cohort of multiple sclerosis patients and healthy controls. Hum Mol Genet. 2013 Oct 15;22(20):4194-205.

28 Toro-Dominguez D, Carmona-Saez P, Alarcon-Riquelme ME. Shared signatures between rheumatoid arthritis, systemic lupus erythematosus and Sjögren's syndrome uncovered through gene expression meta-analysis. Arthritis Res Ther. 2014 Dec 3;16(6):489.

29 Holcomb ZE, Tsalik EL, Woods CW, McClain MT. Host-based peripheral blood gene expression analysis for diagnosis of infectious diseases. J Clin Microbiol. 2017 Feb;55(2): $360-8$.

30 Itkonen O, Parkkinen J, Stenman UH, Hämäläinen E. Preanalytical factors and reference intervals for serum hepcidin LC-MS/ MS method. Clin Chim Acta. 2012 Apr 11; 413(7-8):696-701.

31 Vandesompele J, De Preter K, Pattyn F, Poppe B, Van Roy N, De Paepe A, et al. Accurate normalization of real-time quantitative RTPCR data by geometric averaging of multiple internal control genes. Genome Biol. 2002 Jun 18;3(7):RESEARCH0034.

32 Carrol ED, Salway F, Pepper SD, Saunders E, Mankhambo LA, Ollier WE, et al. Successful downstream application of the PAXgene Blood RNA system from small blood samples in paediatric patients for quantitative PCR analysis. BMC Immunol. 2007;8:20.
33 Beutler E, Felitti V, Ho NJ, Gelbart T. Relationship of body iron stores to levels of serum ferritin, serum iron, unsaturated iron binding capacity and transferrin saturation in patients with iron storage disease. Acta Haematol. 2002;107(3):145-9.

34 Harris EL, McLaren CE, Reboussin DM, Gordeuk VR, Barton JC, Acton RT, et al. Serum ferritin and transferrin saturation in Asians and Pacific Islanders. Arch Intern Med. 2007 Apr 9;167(7):722-6.

35 McLaren CE, Barton JC, Gordeuk VR, Wu L, Adams PC, Reboussin DM, et al. Determinants and characteristics of mean corpuscular volume and hemoglobin concentration in white HFE C282Y homozygotes in the hemochromatosis and iron overload screening study. Am J Hematol. 2007 Oct;82(10):898905.

36 Cao A, Moi P. Regulation of the globin genes. Pediatr Res. 2002 Apr;51(4):415-21.

37 Mettananda S, Gibbons RJ, Higgs DR. Understanding $\alpha$-globin gene regulation and implications for the treatment of $\beta$-thalassemia. Ann N Y Acad Sci. 2016;1368(1):16-24.

38 Watt P, Lamb P, Proudfoot NJ. Distinct negative regulation of the human embryonic globin genes zeta and epsilon. Gene Expr. 1993; 3(1):61-75.

39 Liu JJ, Hou SC, Shen CK. Erythroid gene suppression by NF-kappa B. J Biol Chem. 2003 May 23;278(21):19534-40.

40 Moore G, Knight G, Blann A. Haematology: fundamentals of biomedical science. Oxford: Oxford University Press; 2010

41 Chung SW, Wong SC, Clarke BJ, Patterson M, Walker WH, Chui DH. Human embryonic zeta-globin chains in adult patients with alpha-thalassemias. Proc Natl Acad Sci U S A. 1984 Oct;81(19):6188-91.

42 Chui DH, Wong SC, Chung SW, Patterson M, Bhargava S, Poon MC. Embryonic zeta-globin chains in adults: a marker for alpha-thalassemia-1 haplotype due to a greater than 17.5-kb deletion. N Engl J Med. 1986 Jan 9; 314(2):76-9.

43 Tatu T, Kiewkarnkha T, Khuntarak S, Khamrin S, Suwannasin S, Kasinrerk W. Screening for co-existence of $\alpha$-thalassemia in $\beta$-thalassemia and in $\mathrm{HbE}$ heterozygotes via an enzyme-linked immunosorbent assay for $\mathrm{Hb}$ Bart's and embryonic $\zeta$-globin chain. Int J Hematol. 2012 Apr;95(4):386-93.

44 Albitar M, Peschle C, Liebhaber SA. Theta, zeta, and epsilon globin messenger RNAs are expressed in adults. Blood. 1989;74(2):62937.

45 Lau ET, Kwok YK, Chui DH, Wong HS, Luo HY, Tang MH. Embryonic and fetal globins are expressed in adult erythroid progenitor cells and in erythroid cell cultures. Prenat Diagn. 2001;21(7):529-39.

46 Zhou GL, Xin L, Song W, Di LJ, Liu G, Wu XS, et al. Active chromatin hub of the mouse alpha-globin locus forms in a transcription factory of clustered housekeeping genes. Mol Cell Biol. 2006;26(13):5096-105.
47 Mahajan MC, Karmakar S, Newburger PE, Krause DS, Weissman SM. Dynamics of alpha-globin locus chromatin structure and gene expression during erythroid differentiation of human CD34(+) cells in culture. Exp Hematol. 2009;37(10):1143-56.e3.

48 Ulianov SV, Galitsyna AA, Flyamer IM, Golov AK, Khrameeva EE, Imakaev MV, et al. Activation of the alpha-globin gene expression correlates with dramatic upregulation of nearby non-globin genes and changes in local and large-scale chromatin spatial structure. Epigenetics Chromatin. 2017;10(1):35-19.

$49 \mathrm{He}$ Z, Song D, van Zalen S, Russell JE. Structural determinants of human $\zeta$-globin mRNA stability. J Hematol Oncol. 2014;7:35.

50 Wang L, Harrington L, Trebicka E, Shi HN, Kagan JC, Hong CC, et al. Selective modulation of TLR4-activated inflammatory responses by altered iron homeostasis in mice. J Clin Invest. 2009 Nov;119(11):3322-8.

51 Benesova K, Vujić Spasić M, Schaefer SM, Stolte J, Baehr-Ivacevic T, Waldow K, et al. HFE deficiency impairs pulmonary neutrophil recruitment in response to inflammation. PLoS One. 2012;7(6):e39363.

52 Buffler M, Becker C, Windisch W, Schumann K. Inflammation neither increases hepatic hepcidin nor affects intestinal (59)Fe-absorption in two murine models of bowel inflammation, hemizygous TNF(DeltaARE/+) and homozygous IL-10(-/-) mice. J Trace Elem Med Biol. 2015 Oct;32:162-7.

53 Valenti L, Pelusi S. HFE mutations and iron in hemodialysis patients. Hemodial Int. 2017 Mar 15;21(Suppl 1):S47.

54 Krause A, Neitz S, Mägert HJ, Schulz A, Forssmann WG, Schulz-Knappe P, et al. LEAP-1, a novel highly disulfide-bonded human peptide, exhibits antimicrobial activity. FEBS Lett. 2000;480(2-3):147-50.

55 Ganz T. The role of hepcidin in iron sequestration during infections and in the pathogenesis of anemia of chronic disease. Isr Med Assoc J. 2002;4(11):1043.

56 Khan FA, Fisher MA, Khakoo RA. Association of hemochromatosis with infectious diseases: expanding spectrum. Int J Infect Dis. 2007;11(6):482-7.

57 Lawless MW, Mankan AK, White M, O'Dwyer MJ, Norris S. Expression of hereditary hemochromatosis C282Y HFE protein in HEK293 cells activates specific endoplasmic reticulum stress responses. BMC Cell Biol. 2007 Jul 24; 8:30.

58 Brook M, Tomlinson GH, Miles K, Smith RW, Rossi AG, Hiemstra PS, et al. Neutrophil-derived alpha defensins control inflammation by inhibiting macrophage mRNA translation. Proc Natl Acad Sci U S A. 2016; 113(16):4350-5.

59 Dejonckheere E, Vandenbroucke RE, Libert C. Matrix metalloproteinase 8 has a central role in inflammatory disorders and cancer progression. Cytokine Growth Factor Rev. 2011 Apr;22(2):73-81. 
60 Siller-López F, Sandoval A, Salgado S, Salazar A, Bueno M, Garcia J, et al. Treatment with human metalloproteinase- 8 gene delivery ameliorates experimental rat liver cirrhosis. Gastroenterology. 2004 Apr;126(4):1122-33; discussion 949.

61 Löffek S, Schilling O, Franzke CW. Series "matrix metalloproteinases in lung health and disease": biological role of matrix metalloproteinases: a critical balance. Eur Respir J. 2011 Jul;38(1):191-208.
62 Ganz T, Nemeth E. Hepcidin and iron homeostasis. Biochim Biophys Acta. 2012 Sep; 1823(9):1434-43.

63 Liu J, Sun B, Yin H, Liu S. Hepcidin: a promising therapeutic target for iron disorders: a systematic review. Medicine. 2016 Apr;95(14): e3150.

64 Camaschella C, Nai A, Silvestri L. Iron metabolism and iron disorders revisited in the hepcidin era. Haematologica. 2020 Jan 31; 105(2):260-72.

65 Ganz T, Olbina G, Girelli D, Nemeth E, Westerman M. Immunoassay for human serum hepcidin. Blood. 2008 Nov 15;112(10):42927.
66 Swinkels DW, Girelli D, Laarakkers C, Kroot J, Campostrini N, Kemna EH, et al. Advances in quantitative hepcidin measurements by time-of-flight mass spectrometry. PLoS One. 2008 Jul 16;3(7):e2706.

67 van Dijk BA, Laarakkers CM, Klaver SM, Jacobs EM, van Tits LJ, Janssen MC, et al. Serum hepcidin levels are innately low in HFE-related haemochromatosis but differ between C282Y-homozygotes with elevated and normal ferritin levels. Br J Haematol. 2008 Sep; 142(6):979-85. 